УДК 582.738:547.99:547.913

\title{
СОДЕРЖАНИЕ ФЕНОЛЬНЫХ СОЕДИНЕНИЙ В ПОБЕГАХ СИБИРСКИХ ВИДОВ CARAGANA*
}

\author{
(C) В.В. Партилхаев, Л.М. Танхаева, Д.Н. Оленников

\begin{abstract}
Институт общей и экспериментальной биологии СО РАН, ул. Сахьяновой, 6, Улан-Удэ, 670047 (Россия), e-mail: oldaniil@rambler.ru
\end{abstract}

Проведено исследование фенольных соединений семи видов рода Caragana Fabr., произрастающих на территории Сибири (C. arborescens, C. bungei, C. buryatica, C. frutex, C. jubata, C. pygmaea, C. spinosa). Установлено, что фенольные соединения распределяются неравномерно по органам исследованных видов: наибольшее содержание флавоноидов в листьях отмечено для $C$. arborescens $(107,78$ мг/г), в цветках - для $C$. jubata $(47,24$ мг/г). Общее содержание фенольных соединений в листьях изученных видов составляет 35,00 (C. buryatica) - 112,78 мг/ $\Gamma$ (C. arborescens), в цветках - 36,24 (C. bungei) - 101,07 мг/Г (C. jubata). Для эпидермальных слоев стеблей характерна более высокая концентрация фенольных соединений, чем для луба. В результате хроматографического разделения из C. spinosa выделен и идентифицирован мирицетин-3-O-рутинозид, обнаруженный в данном виде и роде Caragana впервые. Исследование характера накопления флавоноидов в C. spinosa показало, что их максимальное накопление наблюдается в фазу цветения (в побегах до 18,63 мг/г). Экологические условия произрастания C. spinosa влияют на количественное содержание фенольных соединений в побегах, причем наибольшая концентрация отмечена для луговых ценопопуляций. Установлено, что в процессе сушки побегов C. spinosa качественный состав флавоноидов не изменяется, но снижается содержание фенольных соединений на 17,3-33,9\%, а флавоноидов - на 12,6-27,0\%.

Ключевые слова: Caragana, Fabaceae, фенольные соединения, флавоноиды.

Работа выполнена при финансовой поддержке проекта СО РАН № VI.52.1.3 «Молекулярно-клеточные механизмы стресс-индуцированных патологических состояний и коррекция их средствами природного происхождения».

\section{Введение}

Род Caragana Fabr. является представителем семейства Fabaceae, виды которого широко распространены на территории России и имеют лекарственное, декоративное, техническое и кормовое значение [1]. К настоящему времени известно о химическом составе около 30 видов данного рода, в которых установлено присутствие различных классов алифатических, фенольных и терпеновых соединений. Особый интерес в изучении метаболитов рода Caragana Fabr. представляют фенольные соединения (флавоноиды, стильбены и фенилпропаноиды) как основные носители фармакологического эффекта [2].

Род Caragana Fabr. во флоре Сибири представлен 10 видами, обитателями лесов, степей, лугов и гор, жизненной формой которых является кустарник. Несмотря на относительную изученность азиатских видов

Партилхаев Вячеслав Викторович - аспирант лаборатории медико-биологических исследований, тел.: (3012) 43-34-63, e-mail: oldaniil@ rambler.ru

Танхаева Лариса Максимовна - старший научный сотрудник лаборатории медико-биологических исследований, кандидат фармацевтических наук, тел.: (3012) 43-34-63, e-mail: oldaniil@ rambler.ru Оленников Даниил Николаевич - старший научный сотрудник лаборатории медико-биологических исследований, кандидат фармацевтических наук, тел.: (3012) 43-34-63, e-mail: oldaniil@ rambler.ru
Caragana, сведения о фенольных соединениях сибирских видов ограничены. В качестве объектов исследования были выбраны виды Caragana, произрастающие на территории республик Бурятии (C. arborescens, C. buryatica, C. jubata, C. pygmaea, C. spinosa), Тывы (C. bungei) и Иркутской области (C. frutex).

Цель настоящей работы - исследование фенольных соединений побегов семи сибирских видов Caragana.

\footnotetext{
* Данная статья имеет электронный дополнительный материал (приложение), который доступен читателям на сайте журнала. DOI: 10.14258/jcprm.1301143s

* Автор, с которым следует вести переписку.
} 


\section{Экспериментальные условия}

Растительное сырье. Побеги семи видов Caragana были собраны в фазу цветения в районах республик Бурятии, Тывы и Иркутской области в 2009-2011 гг. (табл. 1). Видовая принадлежность определена канд. фарм. наук Г.В. Чехировой (ИОЭБ СО РАН). Образцы сырья хранятся в гербарии ИОЭБ СО РАН.

Общие экспериментальные условия. ВЭТСХ проводили на пластинах с силикагелем Сорбфил ПТСХ-АФ-В (Имид Ltd.); системы растворителей: EtAc - $\mathrm{C}_{2} \mathrm{H}_{4} \mathrm{Cl}_{2}-\mathrm{AcOH}-\mathrm{HCOOH}-\mathrm{H}_{2} \mathrm{O}$ $10: 2,5: 1: 1: 1-1$, толуол - EtAc - НСООН $5: 4: 1-2, \mathrm{PrOH}-\mathrm{CHCl}_{3}-\mathrm{H}_{2} \mathrm{O} 7: 4: 1$ (двукратный подъем на высоту 3,5 и 7 см) - 3; детекторы: 1\% 2-аминоэтилдифенилборинат в EtAc / 5\% ПЭГ 400 в $\mathrm{CH}_{2} \mathrm{Cl}_{2}-1$, $1 \%$-оксидифенил-фосфат в $\mathrm{MeOH} \mathrm{-} \mathrm{2.} \mathrm{Спектрофотометрические} \mathrm{исследования} \mathrm{проводили} \mathrm{на} \mathrm{спектрофо-}$ тометре СФ-2000 (ОКБ Спектр). МС-анализ проводили на масс-спектрометре высокого разрешения МАТ 8200 (Finnigan). Спектры ${ }^{13} \mathrm{C}$-ЯМР регистрировали на ЯМР-спектрометре VXR 500S (Varian) с рабочей частотой 125,7 МГц для $1 \%$ растворов веществ в ДМСО- $d_{6}$. ВЭЖХ проводили на жидкостном хроматографe Summit (Dionex). В работе использованы стандартные образцы веществ: рутин, кверцетин (Sigma); остальные реактивы имели степень чистоты ч.д.а.

Суммарное содержание флавоноидов (ОФл) определяли спектрофотометрическим методом с применением дифференциального варианта анализа (ДМ-1); общее содержание фенольных соединений (ОФС) определяли методом Фолина с использованием рутина в качестве вещества сравнения [3]. Условия хроматографического анализа методами ВЭТСХ и ВЭЖХ описаны нами ранее $[4,5]$.

Экстракцию и фракционирование экстрактивных веществ проводили по методу [4]. Бутанольную фракцию (6 г) хроматографировали с применением колоночной хроматографии на Сефадексе LH-20 $\left(4 \times 30\right.$ см) в градиентной системе ЕtОН - $\mathrm{H}_{2} \mathrm{O}(96: 4 \rightarrow 0: 100)$ с последующей КХ на полиамиде $(5 \times 4$ см, элюент $\left.-\mathrm{EtOH}-\mathrm{H}_{2} \mathrm{O} 96: 4 \rightarrow 0: 100\right), \mathrm{SiO}_{2}\left(2 \times 50\right.$ см, элюент $\left.-\mathrm{CHCl}_{3}-\mathrm{EtOH} 100: 0 \rightarrow 70: 30\right)$ и препаративной ТСХ (система растворителей - 1). В результате разделения было выделено 5 соединений, идентифицированных как рутин (кверцетин-3-O-рутинозид, 46 мг) [6], нарциссин (изорамнетин-3-Oрутинозид, 12 мг) [7], (-)-эпигаллокатехин (5 мг) [8], никотифлорин (кемпферол-3-O-рутинозид, 8 мг) [6] и мирицетин-3-O-рутинозид (7 мг).

Мирицетин-3-O-рутинозид. $\mathrm{C}_{27} \mathrm{H}_{30} \mathrm{O}_{17}$. Т.пл. $>300{ }^{\circ} \mathrm{C}$. УФ-спектр ( $\lambda_{\max }$, нм): EtOH 231, $259,356$. +ESI-MC (m/z,\%): 627 [M+H] ${ }^{+} .{ }^{13} \mathrm{C}-$ ЯМР-спектр (125 МГц, ДМСО- $\left.d_{6}\right):$ 17,98 (Rha, C-6"'), 68,02 (Glc, C-6"'), 69,11 (Rha, C-5"'), 70,92 (Rha, C-2'"'), 71,64 (Rha, C-3"'), 72,57 (Glc, C-4"'), 73,82 (Rha, C-4"'), 75,09 (Glc, C-2"'), 76,59 (Glc, C-5"), 77,43 (Glc, C-3"'), 93,90 (C-8), 99,63 (C-6), 101,73 (Rha, C-1"'), 103,63 (Glc, C-1"'), 105,40 (C-10), 109,22 (C-2', C-6'), 122,45 (C-1'), 135,26 (C-3), 137,84 (C-4'), 145,79 (C-3', C-5'), 158,81 (C-9), 159,37 (С-2), 163,01 (С-5), 165,99 (С-7), 179,41 (С-4). В гидролизате (2\% ТФУ, 4 ч, $\left.90{ }^{\circ} \mathrm{C}\right):$ мирицетин (ВЭТСХ, система растворителей - 2, детектор - 1), глюкоза и рамноза (ВЭТСХ, система растворителей - 3, детектор - 2).

Таблица 1. Характеристика растительного сырья

\begin{tabular}{|c|c|c|}
\hline Вид & Номер сырья, место сбора, координаты & Дата сбора \\
\hline $\begin{array}{l}\text { C. arborescens Lam. } \\
\text { (к. древовидная) }\end{array}$ & $\begin{array}{c}\text { Респ. Бурятия, г. Улан-Удэ, Ботанический сад Бурятского научного } \\
\text { центра }\end{array}$ & 15.06 .2011 \\
\hline C. bungei Ledeb. (к. Бунге) & Респ. Тыва, Тес-Хемский р-он, с. Самагалтай & 08.08.2009 \\
\hline $\begin{array}{l}\text { C. buryatica Peschkova } \\
\text { (к. бурятская) }\end{array}$ & Респ. Бурятия, Иволгинский р-он, с. Хурумша & 23.061.2010 \\
\hline $\begin{array}{l}\text { C. frutex (L.) C. Косh } \\
\text { (к. кустарниковая) }\end{array}$ & $\begin{array}{c}\text { Иркутская обл., г. Иркутск, Ботанический сад Иркутского } \\
\text { государственного университета }\end{array}$ & 30.05.2011 \\
\hline $\begin{array}{l}\text { C. jubata (Pallas) Poiret } \\
\text { (к. гривастая) }\end{array}$ & Респ. Бурятия, Окинский р-он, с. Хаара-Хужир & 18.06.2011 \\
\hline $\begin{array}{l}\text { C. pygmaea }(\mathrm{L} .) \mathrm{DC} \\
\text { (к. карликовая) }\end{array}$ & Респ. Бурятия, Мухоршибирский р-он, с. Галтай & 19.06.2010 \\
\hline \multirow{3}{*}{$\begin{array}{l}\text { C. spinosa (L.) DC } \\
\text { (к. колючая) }\end{array}$} & Респ. Бурятия, Иволгинский р-он, с. Средний Убукун, луг (образец CS-SU) & 15.06.2011 \\
\hline & Респ. Бурятия, Иволгинский р-он, с. Нижний Убукун, степь (образец CS-NU) & 15.06.2011 \\
\hline & Респ. Бурятия, Иволгинский р-он, с. Оронгой, солончак (образец CS-OR) & 15.06.2011 \\
\hline
\end{tabular}


Сушку побегов $C$. spinosa проводили воздушно-сухим (затемненное проветриваемое помещение, $25-28{ }^{\circ} \mathrm{C}, 5-7$ сут.) и жаровым способом (сушильный шкаф, 70-80 ${ }^{\circ} \mathrm{C}, 3-4$ ч). Для экстракции свежего сырья точную навеску (2 г) переносили в предварительно охлажденную керамическую ступку, заливали 5 объемами жидкого азота и после удаления основной части газа быстро гомогенизировали (2-3 мин). Далее сырье переносили в колбу со шлифом вместимостью 150 мл, ступку промывали 15 мл 96\% этанола в ту же колбу, приливали 35 мл 96\% этанола, присоединяли обратный холодильник и нагревали на кипящей водяной бане в течение 30 мин. После охлаждения извлечение фильтровали в мерную колбу вместимостью 100 мл. Экстракцию повторяли еще раз с 50 мл $60 \%$ этанола в тех же условиях. Объем объединенного раствора доводили до метки 60\% этанолом и анализировали спектрофотометрическим методом.

Количественный анализ с применением спектрофотометрии и ВЭЖХ был проведен в 11- и 5кратной повторности, соответственно, после чего результаты были статистически обработаны и представлены в виде $\left(x_{\text {средн }} \pm \Delta E\right)$.

\section{Результаты и их обсуждение}

Предварительные исследования показали, что для количественного анализа флавоноидов в морфологических группах семи исследованных видов допустимым является использование дифференциального варианта спектрофотометрического анализа с применением $\mathrm{AlCl}_{3}$ в качестве комплексообразователя. Максимумы дифференциальных спектров спиртовых извлечений из листьев и цветков находились в области 410-415 нм, а из стеблей - в области 428-432 нм, поэтому в качестве веществ сравнения были выбраны рутин и кверцетин соответственно. Исключением являлся образец листьев $C$. frutex, экстремум спектра которого приходился на область 390-400 нм.

Общее содержание фенольных соединений в листьях составило 35,00 (C. buryatica) - 112,78 мг/Г (C. arborescens), в цветках - 36,24 (C. bungei) - 101,07 мг/Г (C. jubata), в эпидермисе стеблей - 12,45 (C. buryatica) - 34,91 мг/Г (C. arborescens), в лубе стеблей - 1,25 (C. buryatica) - 19,58 мг/Г $(C$. frutex) (табл. 2). Распределение фенольных соединений по органам семи видов Caragana было не одинаково; так, для C. arborescens и $C$. bungei накопление данного класса соединений характерно в листьях, а для остальных видов - в цветках. В стеблях наибольшая концентрация была отмечена в эпидермальных слоях, причем доминирование составляло от 1,71 (C. frutex) до 9,96 раз (C. buryatica). Содержание флавоноидов в листьях Caragana находилось в диапазоне 14,95 (C. pygmaea) - 107,78 мг/Г (C. arborescens), в цветках 9,20 (C. spinosa) - 47,24 мг/Г (C. jubata), в эпидермисе стеблей - 1,48 (C. jubata) - 20,78 мг/Г (C. arborescens), в лубе стеблей - от следовых (C. bungei, C. frutex, C. jubata) до 3,42 мг/Г (C. arborescens). Следует отметить, что распределение флавоноидов по морфологическим группам было несколько отличным от такового общих фенольных соединений: доминирование в листьях было отмечено для всех видов кроме C. jubata и C. pygmaea, причем для C. arborescens, C. buryatica и C. spinosa содержание флавоноидов в эпидермисе стеблей превышало таковое в цветках.

С применением хроматографического анализа (ВЭТСХ, ВЭЖХ) было установлено, что состав флавоноидов изученных видов Caragana типичен: доминирующими соединениями листьев и цветков были флавонол-гликозиды - рутин (кверцетин-3-O-рутинозид), нарциссин (изорамнетин-3-O-рутинозид) и изокверцитрин (кверцетин-3-O-глюкозид); в стеблях преобладали агликоны флавоноидов - кверцетин и кемпферол (данные не представлены). В листьях C. frutex также отмечено высокое содержание моно- и дикофеилхинных кислот, а в листьях $C$. arborescens и $C$. jubata - формононетина и его гликозидов. Относительное содержание моногликозидов кверцетина, изорамнетина и кемпферола в листьях и цветках $C$. jubata значительно выше, чем в других изученных видах. Согласно данным литературы присутствие кверцетина было ранее выявлено в C. arborescens [9], C. alaica [10], C. intermedia [11], C. jubata [12], C. opulens [13], C. pygmaea [14], C. sinica [15], C. spinosa [16]; кемпферола - в C. spinosa [16]; изорамнетина - в $C$. frutex [17], C. jubata [12]; рутина - в C. arborescens [9], C. aurantiaca [18], C. pygmaea [14], C. rosea [19], C. sinica [20], C. spinosa [16]; нарциссина - в C. aurantiaca [18], C. pygmaea [14], C. sinica [15], C. spinosa [16]; изокверцитрина - в C. arborescens [9], C. alaica [10], C. sinica [15], C. spinosa [16]. Учитывая сведения о составе флавоноидов рода Caragana, можно предположить, что наличие кверцетина, изорамнетина и кемпферола и их гликозидов является хемотаксономическим признаком данного рода. 
Таблица 2. Содержание фенольных соединений (ОФС) и флавоноидов (ОФл) в морфологических группах семи видов Caragana, мг/г возд.-сух. сырья $(n=11)$

\begin{tabular}{|c|c|c|c|c|}
\hline \multirow{3}{*}{ Вид } & \multicolumn{4}{|c|}{ Морфологическая группа } \\
\hline & \multirow{2}{*}{ Листья } & \multirow{2}{*}{ Цветки } & \multicolumn{2}{|c|}{ Стебли } \\
\hline & & & Эпидермис & Луб \\
\hline \multicolumn{5}{|c|}{ ОФС } \\
\hline C. arborescens & $112,78 \pm 3,95$ & $40,59 \pm 1,46$ & $34,91 \pm 1,36$ & $8,75 \pm 0,34$ \\
\hline C. bungei & $40,09 \pm 0,82$ & $36,24 \pm 0,64$ & $12,60 \pm 0,38$ & $1,94 \pm 0,06$ \\
\hline C. buryatica & $35,00 \pm 1,21$ & $40,25 \pm 0,81$ & $12,45 \pm 0,44$ & $1,25 \pm 0,04$ \\
\hline C. frutex & $41,92 \pm 1,46$ & $76,45 \pm 2,52$ & $33,45 \pm 1,10$ & $19,58 \pm 0,66$ \\
\hline C. jubata & $97,19 \pm 3,11$ & $101,07 \pm 3,64$ & $21,90 \pm 0,74$ & $8,51 \pm 0,28$ \\
\hline C. pygmaea & $11,48 \pm 0,24$ & $36,76 \pm 0,77$ & $24,18 \pm 0,72$ & $9,93 \pm 0,29$ \\
\hline C. spinosa & $37,65 \pm 0,82$ & $43,42 \pm 0,52$ & $25,73 \pm 0,83$ & $3,35 \pm 0,11$ \\
\hline \multicolumn{5}{|c|}{ ОФл } \\
\hline C. arborescens & $107,78 \pm 4,20$ & $16,71 \pm 0,51$ & $20,78 \pm 0,58$ & $3,42 \pm 0,12$ \\
\hline C. bungei & $29,32 \pm 0,58$ & $18,67 \pm 0,37$ & $2,13 \pm 0,04$ & сл. $^{\text {a }}$ \\
\hline C. buryatica & $30,58 \pm 0,40$ & $12,90 \pm 0,16$ & $15,37 \pm 0,31$ & $2,77 \pm 0,05$ \\
\hline C. frutex & H.o. ${ }^{\sigma}$ & $17,46 \pm 0,38$ & $4,89 \pm 0,11$ & сл. \\
\hline C. jubata & $37,14 \pm 0,68$ & $47,24 \pm 0,93$ & $1,48 \pm 0,03$ & сл. \\
\hline C. pygmaea & $14,95 \pm 0,16$ & $16,77 \pm 0,18$ & $16,07 \pm 0,32$ & $3,41 \pm 0,06$ \\
\hline C. spinosa & $31,62 \pm 0,37$ & $9,20 \pm 0,11$ & $18,39 \pm 0,36$ & $1,12 \pm 0,02$ \\
\hline
\end{tabular}

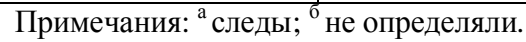

Согласно систематической структуре семейства Fabaceae род Caragana Fabr. является представителем группы Caragana, в которую входит еще четыре рода: Calophaca Fisch. ex DC. (майкараган), Halimodendron Fisch. ex DC. (чингиль), Spongiocarpella Yakovl. et Ulzij. (спонгиокарпелла) и Chesneya Lindl. ex Endl. (чезнея) [21]. Информация о составе фенольных соединений данной группы крайне ограничена; известно о присутствии в надземной части Halimodendron halodendron (Pall.) Voss. кверцетина, 3-O-метилкверцетина, 3,3'-O-диметилкверцетина и нарциссина [22], поэтому выводы о хемотаксономических признаках для группы Caragana в настоящее время невозможны.

Более детальное исследование характера накопления фенольных соединений было проведено для C. spinosa, широко распространенной на территории республики Бурятии, побеги которой рассматриваются в качестве перспективного лекарственного растительного сырья. Ранее нами был исследован состав фенольных соединений побегов C. spinosa и установлено присутствие флавонолов в форме агликонов, моно- и биозидов, в том числе 3-O-рутинозидов кверцетина, изорамнетина и кемпферола $[4,5]$. В результате хроматографического разделения из бутанольной фракции, наряду с рутином, нарциссином, никотифлорином и (-)-эпи-

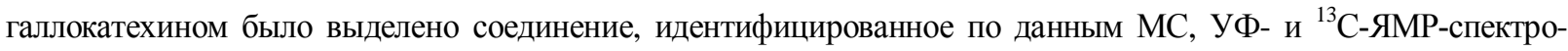
скопии как 3,5,7,3',4',5'-тетрагидроксифлавона 3-O-рамноглюкозид (мирицетин-3-O-рутинозид). Наличие данного флавонол-гликозида выявлено в C. spinosa и роде Caragana впервые. Ранее мирицетин-3-O-рутинозид был обнаружен в других видах семейства Fabaceae: Acacia ehrenbergiana Hayne [23] и Clitoria ternatea Linn. [24].<smiles>[R1]Oc1c(-c2cc(O)c(O)c(O)c2)oc2cc(O)cc(O)c2c1=O</smiles>

Изучение динамики накопления фенольных соединений в течение вегетационного периода в морфологических группах $C$. spinosa показало, что наибольшая концентрация данного класса соединений отмечается в период цветения: в стеблях - 12,26 и 10,36, в листьях - 37,65 и 31,62, в цветках - 43,42 и 9,20 мг/г соответственно для общих фенольных соединений и флавоноидов (табл. 3). Необходимо отметить, что фенольные соединения присутствовали во всех частях растения, в том числе в семенах и околоплодниках, причем в последних содержание флавоноидов составило 6,01 мг/г.

Максимальная концентрация фенольных соединений и флавоноидов в суммарном сырье - побегах C. spinosa также была характерна для фазы массового цветения: 27,92 и 18,63 мг/г соответственно (рис. 1). Выявленные особенности накопления свидетельствовали о том, что оптимальным временем сбора побегов C. spinosa является фаза цветения. 
Таблица 3. Содержание фенольных соединений (ОФС) и флавоноидов (ОФл) в морфологических группах C. spinosa в течение вегетационного периода, мг/г возд.-сух. сырья $(n=11)$

\begin{tabular}{|c|c|c|c|c|c|c|}
\hline \multirow{2}{*}{ Дата сбора } & \multicolumn{6}{|c|}{ Морфологическая группа } \\
\hline & Стебли & Листья & Бутоны & Цветки & Створки & Семена \\
\hline \multicolumn{7}{|c|}{ ОФС } \\
\hline 28.04 .2010 & $11,17 \pm 0,23$ & - & - & - & - & - \\
\hline 28.05.2010 & $9,57 \pm 0,21$ & $30,22 \pm 0,63$ & - & - & - & - \\
\hline 2.06 .2010 & $9,92 \pm 0,22$ & $30,27 \pm 0,67$ & $40,56 \pm 0,89$ & - & - & - \\
\hline 09.06 .2010 & $12,15 \pm 0,26$ & $32,49 \pm 0,71$ & $34,26 \pm 0,75$ & $37,92 \pm 0,83$ & - & - \\
\hline 23.06.2010 & $12,26 \pm 0,27$ & $37,65 \pm 0,82$ & - & $43,42 \pm 0,52$ & - & - \\
\hline 29.07.2010 & $8,66 \pm 0,10$ & $31,81 \pm 0,38$ & - & - & $25,70 \pm 0,33$ & $18,74 \pm 0,24$ \\
\hline \multicolumn{7}{|c|}{ ОФл } \\
\hline 28.04 .2010 & $9,40 \pm 0,11$ & - & - & - & - & - \\
\hline 28.05 .2010 & $5,58 \pm 0,07$ & $29,42 \pm 0,38$ & - & - & - & - \\
\hline 2.06.2010 & $5,92 \pm 0,08$ & $28,16 \pm 0,31$ & $13,70 \pm 0,16$ & - & - & - \\
\hline 9.06 .2010 & $6,17 \pm 0,07$ & $28,69 \pm 0,34$ & $10,58 \pm 0,12$ & $8,47 \pm 0,10$ & - & - \\
\hline 23.06.2010 & $10,36 \pm 0,12$ & $31,62 \pm 0,37$ & - & $9,20 \pm 0,11$ & - & - \\
\hline 29.07.2010 & $5,53 \pm 0,07$ & $30,15 \pm 0,35$ & - & - & $6,01 \pm 0,07$ & $3,74 \pm 0,04$ \\
\hline
\end{tabular}

Учитывая высокую экологическую приспособляемость $C$. spinosa к условиям внешней среды, нами проведен анализ фенольных соединений в сырье, собранном в трех неантропогенных экотопах: разнотравный луг (образец CS-SU), степь (образец CS-NU) и солончак (образец CS-OR) (табл. 4). Установлено, что наибольшее содержание фенольных соединений и флавоноидов в побегах наблюдалось для сырья, произрастающего в условиях луга (64,01 и 13,02 мг/г соответственно). Исследования показали, что условия произрастания $C$. spinosa влияют на характер распределения веществ по морфологическим группам. Так, для луговой и солончаковой популяций накопление фенольных соединений отмечено в листьях (127,54 и 94,98 мг/г соответственно), в то время как для степной популяции - в цветках (112,48 мг/г). Максимальное содержание флавоноидов для трех типов сырья наблюдалось в листьях (21,78-27,14 мг/г), а минимальное в стеблях (1,43-2,63 мг/г). Значения данного показателя для колючек указывало на промежуточное положение данной метаморфозы между стеблями и листьями (7,07-9,92 мг/г), что также подтверждалось ранними данными о составе фенольных соединений [4].

Согласно данным ВЭЖХ экологические условия не оказывали влияние на качественный состав флавоноидов, однако следует отметить, что для сырья CS-OR была характерна повышенная концентрация моногликозидов кверцетина и изорамнетина, а для CS-SU - флавонол рутинозидов (табл. 5). Содержание рутина в образцах CS-SU, CS-NU и CS-OR составило 4,28, 3,84 и 3,46 мг/г соответственно, нарциссина - 2,99, 2,93 и 2,91 мг/г соответственно.

Известно, что процесс сушки растительного сырья оказывает влияние на его химический состав и в большинстве случаев приводит к снижению содержания действующих групп соединений. Для оценки подобных изменений проведено сравнительное исследование качественного состава и количественного содержания фенольных соединений в побегах C. spinosa, высушенных воздушно-сухим (способ 1) и жаровым (способ 2) способами. Дополнительно исследовались свежие побеги C. spinosa, анализ которых проводился не позднее 1 ч после сбора сырья. Установлено, что потери общих фенольных соединений в побегах были минимальные $(17,3 \%)$ при медленной сушке и составляли при быстрой сушке до 33,9\% от исходного содержания (табл. 6).

Рис. 1. Содержание фенольных соединений (ОФС) и флавоноидов (ОФл) в побегах C. spinosa в течение вегетационного периода. По оси абсиисс - фаза вегетации: 1 - начало вегетации, 2 - вегетация, 3 - бутонизация, 4 - начало цветения, 5 - массовое цветение, 6 - плодоношение. Над столбцами указаны значения содержания, мг/г возд.-сух. сырья

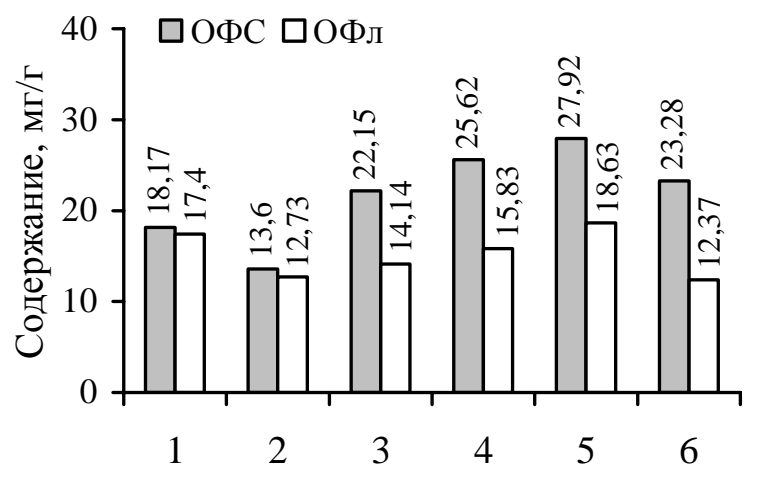


Для флавоноидов эти изменения носили иной характер: быстрая сушка позволяла сохранить до $87,4 \%$ веществ от исходного уровня, против 73,0\% при медленной сушке. Качественный состав флавоноидов не претерпевал изменений, однако следует отметить более низкое содержание 3-O-глюкозидов кверцетина и изорамнетина, а также свободных агликонов в сырье быстрой сушки, что обусловлено отсутствием влияния гидролаз, инактивирующихся при высокой температуре (рис. 2).

Таблица 4. Содержание фенольных соединений (ОФС) и флавоноидов (ОФл) в морфологических группах C. spinosa трех ценопопуляций, мг/г возд.-сух. сырья $(n=11)$

\begin{tabular}{c|c|c|c|c|c|c}
\hline \multirow{2}{*}{$\begin{array}{c}\text { Морфологи- } \\
\text { ческая групп }\end{array}$} & \multicolumn{2}{|c}{ Сенопопуляция } \\
\cline { 2 - 7 } & ОФС & ОФл & ОФС & ОФл & ОФС & ОФл \\
\cline { 2 - 7 } & $64,01 \pm 2,24$ & $13,02 \pm 0,26$ & $57,73 \pm 2,02$ & $11,32 \pm 0,21$ & $54,55 \pm 1,90$ & $10,64 \pm 0,21$ \\
Побеги & $127,54 \pm 4,46$ & $27,14 \pm 0,54$ & $97,69 \pm 3,41$ & $21,78 \pm 0,43$ & $94,98 \pm 3,32$ & $26,08 \pm 0,52$ \\
Листья & $87,83 \pm 3,07$ & $12,17 \pm 0,21$ & $112,48 \pm 3,93$ & $12,24 \pm 0,23$ & $89,36 \pm 3,12$ & $10,99 \pm 0,20$ \\
Цветки & $19,57 \pm 0,69$ & $1,43 \pm 0,02$ & $23,65 \pm 0,81$ & $2,23 \pm 0,04$ & $18,95 \pm 0,66$ & $2,63 \pm 0,05$ \\
Стебли & $24,34 \pm 0,85$ & $9,92 \pm 0,19$ & $27,52 \pm 0,96$ & $8,85 \pm 0,17$ & $23,99 \pm 0,84$ & $7,07 \pm 0,14$ \\
Колючки & \multicolumn{4}{|c|}{} \\
\hline
\end{tabular}

Таблица 5. Содержание индивидуальных флавоноидов в побегах C. spinosa трех ценопопуляций, мкг/г возд.-сух. сырья $(n=5)$

\begin{tabular}{l|c|c|c}
\hline \multicolumn{1}{c|}{ Соединение } & \multicolumn{3}{|c}{ Ценопопуляция } \\
\cline { 2 - 4 } & CS-SU & CS-NU & CS-OR \\
\hline Изорамнетин-3-O-глюкозид & $392,20 \pm 13,72$ & $157,94 \pm 5,05$ & $1138,53 \pm 15,41$ \\
Кверцетин-3-O-глюкозид & $1072,55 \pm 34,32$ & $842,72 \pm 28,65$ & $635,18 \pm 20,96$ \\
Кемпферол-3-O-рутинозид & $1769,97 \pm 60,18$ & $836,4328,44$ & $2911,06 \pm 98,64$ \\
Изорамнетин-3-O-рутинозид & $2985,45 \pm 98,52$ & $2934,35 \pm 90,96$ & $3463,21 \pm 124,61$ \\
Кверцетин-3-O-рутинозид & $4276,11 \pm 141,11$ & $3840,29 \pm 130,57$ & $507,28 \pm 17,24$ \\
Мирицетин-3-О-рутинозид & $626,35 \pm 21,29$ & $559,81 \pm 17,91$ & 1578,83 \\
Флавонол-монозиды & 1464,75 & 1001,66 & 7516,73 \\
Флавонол-биозиды & 9657,88 & 7170,88 & \\
\hline
\end{tabular}

Таблица 6. Содержание фенольных соединений (ОФС) и флавоноидов (ОФл) в свежих и высушенных побегах $C$. spinosa $(n=11)$

\begin{tabular}{|c|c|c|c|c|c|c|}
\hline \multirow{2}{*}{ Вид сырья } & \multicolumn{2}{|c|}{ Побеги } & \multicolumn{2}{|c|}{ Листья } & \multicolumn{2}{|c|}{ Цветки } \\
\hline & ОФС & ОФл & ОФС & ОФл & ОФС & ОФл \\
\hline \multicolumn{7}{|l|}{ Свежее сырье } \\
\hline мг/Г свежего сырья & 20,61 & 9,67 & 27,19 & 15,26 & 27,24 & 7,93 \\
\hline мг/Г возд.-сух. сырья ${ }^{a}$ & 44,52 & 20,88 & 81,57 & 45,78 & 87,17 & 25,38 \\
\hline \multicolumn{7}{|c|}{ Возд.-сух. сырье, мг/Г возд.-сух. сырья } \\
\hline способ 1 & 36,81 & 15,24 & 57,74 & 28,59 & 50,41 & 15,52 \\
\hline способ 2 & 29,87 & 18,24 & 55,33 & 22,41 & 52,05 & 13,83 \\
\hline
\end{tabular}

${ }^{\mathrm{a}}$ с учетом коэффициента усушки.

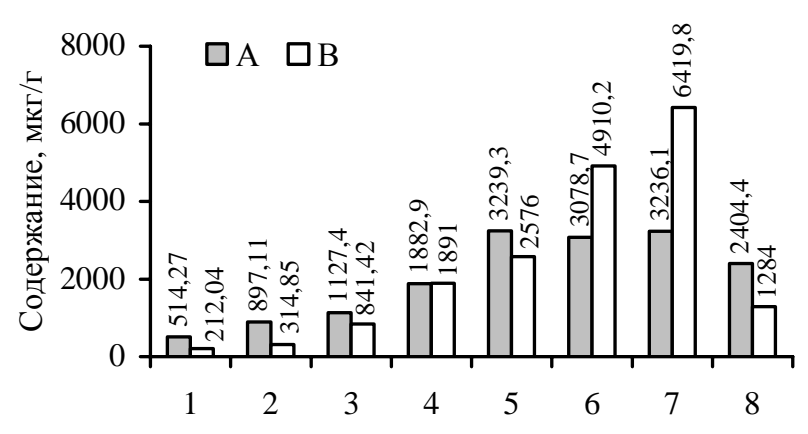

Рис. 2. Содержание индивидуальных флавоноидов в высушенных побегах C. spinosa. Способ сушки: A - 1, В - 2. По оси абсиисс - соединение: 1 - кемпферол,

2 - кверцетин, 3 - изорамнетин-3-O-глюкозид, 4 - кверцетин-3-O-глюкозид, 5 - кемпферол-3$O$-рутинозид, 6 - изорамнетин-3-O-рутинозид, 7 - кверцетин-3-O-рутинозид, 8 - мирицетин3-O-рутинозид. Над столбцами указаны значения содержания, мкг/Г возд.-сух. сырья

\section{Выводы}

1. Проведенные исследования показали, что сибирские представители рода Caragana Fabr. являются накопителями фенольных соединений, в том числе флавоноидов, и после проведения дополнительного 
изучения некоторые из них (C. arborescens, C. jubata, C. spinosa) можно рассматривать в качестве перспективного лекарственного растительного сырья.

2. Учитывая недостаточную изученность других родов группы Caragana семейства Fabaceae, можно рекомендовать проведение исследований химического состава видов Calophaca, Halimodendron и Chesneya, произрастающих на территории России, с целью формирования более полной хемосистематической картины данной группы.

3. В побегах C. spinosa, наряду с ранее выделенными 3-O-рутинозидами кемпферола, изорамнетина и кверцетина впервые выявлено присутствие мирицетин-3-O-рутинозида. Установлено, что фаза сбора сырья, экологические условия произрастания, а также способ сушки сырья влияют в большей степени на количественное содержание фенольных соединений; изменения в качественном составе флавоноидов не обнаружены.

\section{Электронный дополнительный материал}

В электронном дополнительном материале приведена методика количественного определения суммарного содержания флавоноидов в побегах Caragana.

\section{Список литературы}

1. Флора СССР / ред. В.Л. Комаров. Т. ХІ. М. ; Л., 1945. С. 327-368.

2. Meng Q., Niu Y., Roubin R.H., Hanrahan J.R. Ethnobothany, phytochemistry and pharmacology of the genus Caragana used in traditional Chinese medicine // J. Ethnopharmacol. 2009. Vol. 124. Pp. 350-368.

3. Shetty K., Curtis O.F., Levin R.E., Witkowsky R., Ang W. Prevention of vitrification associated with in vitro shoot culture of oregano (Origanum vulgare) by Pseudomonas spp. // J. Plant Physiol. 1995. Vol. 147. Pp. 447-451.

4. Olennikov D.N., Tankhaeva L.M., Partilkhaev V.V. Chemical investigation of Caragana spinosa runners // Chem. Nat. Compd. 2012. Vol. 47, N6. Pp. 988-990.

5. Olennikov D.N., Partilkhaev V.V. Isolation and densitometric HPTLC analysis of rutin, narcissin, nicotiflorin and isoquercitrin in Caragana spinosa shoots // J. Planar Chrom. Modern TLC. 2012. Vol. 25, N1. Pp. 30-35.

6. Hou W., Lin R., Lee T., Huang Y., Hsu F., Lee M. The phenolic constituents and free radical scavenging activities of Gynura formosana Kiamnra // J. Sci. Food Agric. 2005. Vol. 85. Pp. 615-621.

7. Lu Y., Sun Y., Foo L.Y., McNaab W.C., Molan A.L. Phenolic glycosides of foliage legume Onobrychis viciifolia // Phytochemistry. 2000. Vol. 55. Pp. 67-75.

8. Ma Ch., Li B., Xu Q., Zhang G. Chemical study on the stem of Lonicera landeolata // Chin. J. Appl. Environ. Biol. 2006. Vol. 12. Pp. 487-495.

9. Boinik V.V., Batyuk N.V., Kovalev V.N. Flavonoids of Caragana arborescens // Chem. Nat. Compd. 1986. Vol. 22. P. 351.

10. Butayarov A.V., Batirov E.Kh., Tadzhibaev M.M., Yuldashev M.P. Flavonoids of Caragana alaica // Chem. Nat. Compd. 1999. Vol. 35. Pp. 628-630.

11. Shi J., Chen B., Sun Z.H., Hu C.Q. Studies on flavonoid constituents of Caragana intermedia // Acta Pharm. Sin. 2003. Vol. 38. Pp. 599-602.

12. Umarov A., Batyuk V.S., Khaletskii A.M. Flavonols of Caragana jubata // Chem. Nat. Compd. 1971. Vol. 7. Pp. 499-500.

13. Yang Z., Xiao A., Zhang X., Li T., Li S. Chemical constituents from bark of Caragana opulens // J. Chin. Med. Mater. 2008. Vol. 31. Pp. 855-857.

14. Polovinko A.E., Yakovlev G.P. Flavonoids of Caragana pygmaea // Chem. Nat. Compd. 1985. Vol. 21. Pp. $252-253$.

15. Tai Z.-G., Cai L., Dai L., Sun W.-J., Zhe W., Yang Y.-B., Cao Q.-E., Ding Z.-T. Antioxidant activities of Caragana sinica flower extracts and their main chemical constituents // Molecules. 2010. Vol. 15. P. 6722-6732.

16. Shpekina G.A. Flavonoids of Caragana spinosa // Chem. Nat. Compd. 1990. Vol. 26. P. 95.

17. Boinik V.V., Kovalev V.N. Flavonoids of Caragana frutex // Chem. Nat. Compd. 1987. Vol. 23. P. 504.

18. Polovinko A.E., Shostakovskaya N.G. Flavonoids of Caragana aurantiaca // Chem. Nat. Compd. 1987. Vol. 23. P. 375.

19. Qiu E.C., Xiang X.Z., Pan J.C., Tu Z.B. Studies on the chemical constituents of the root of Caragana rosea Turcz. // J. Hebei Norm. Univ. (Nat. Sci. Ed.). 1997. Vol. 21. Pp. 99-101.

20. Ma C.W., Ham I., Whang W.K. The flavonoids from the Caragana chamlagu leaves // Yakhak Hoechi. 1999. Vol. 43. Pp. 143-149.

21. Яковлев Г.П. Бобовые земного шара. Л., 1991. С. 108-112.

22. Wang J., Gao H., Zhao J., Wang Q., Zhou L., Han J., Yu Z., Yang F. Preparative separation of phenolic compounds from Halimodendron halodendron by high-speed counter-current chromatography // Molecules. 2010. Vol. 15. Pp. $5998-6007$.

23. Gaara A.H., Nassar M.I., Younis M., Elmegeed G.A., Mabry T.J., Pare P.W. Biologically active polyphenolic compounds from Acacia ehrenbergiana // Rev. Latinoamer. Quím. 2008. Vol. 36. Pp. 52-59.

24. Patil A.P., Patil V.R. Clitoria ternatea Linn.: An overview // Int. J. Pharm. Res. 2011. Vol. 3. Pp. 20-23. 
Partilkhaev V.V., Tankhaeva L.M., Olennikov D.N. ${ }^{*}$ PHENOLIC COMPOUNDS CONTENT IN SHOOTS OF SIBERIAN CARAGANA SPECIES

Institute of General and Experimental Biology SD RAS, Sakh'yanovoy st., 6, Ulan-Ude, 670047 (Russia), e-mail: oldaniil@ rambler.ru

A study of phenolic compounds of the seven species of Caragana Fabr. genus growing on the territory of Siberia (C. arborescens, C. bungei, C. buryatica, C. frutex, C. jubata, C. pygmaea, C. spinosa) was realized. It is established that phenolic compounds are unevenly distributed in organs of studied species: the highest content of flavonoids in the leaves was observed for C. arborescens $(107,78 \mathrm{mg} / \mathrm{g})$ and in the flowers - for $C$. jubata $(47,24 \mathrm{mg} / \mathrm{g})$. The total contents of phenolic compounds in the leaves of the species were $35,00($ C. buryatica $)-112,78 \mathrm{mg} / \mathrm{g}($ C. arborescens $)$ and in the flowers $-36,24(C$. bungei) $-101,07 \mathrm{mg} / \mathrm{g}($ C. jubata). To stem epidermal layers was observed a higher concentration of phenolic compounds than the same for inner bark of the stem. As a result of the chromatographic separation from C. spinosa was isolated and identified myricetin-3-O-rutinoside found in this species and Caragana genus for the first time. The investigation of the flavonoids accumulation in $C$. spinosa was showed that their maximum accumulation observed at the flowering period (in shoots up to 18,63 $\mathrm{mg} / \mathrm{g}$ ). The environmental growth conditions of $C$. spinosa affected on the quantitative content of phenolic compounds in the shoots, and the highest concentration was observed for meadow cenopopulations. It was established that the drying process of C. spinosa shoots does not change the composition of flavonoids, but reduced the total phenolic content in $17,3-33,9 \%$ and total flavonoids content in 12,6-27,0\%.

Keywords: Caragana, Fabaceae, phenolic compounds, flavonoids.

\section{References}

1. Flora SSSR / red. V.L. Komarov. [Flora of the USSR. Ed. V.L. Komarov]. Moscow ; Leningrad, 1945, vol. XI, pp. 327-368. (in Russ.)

2. $\quad$ Meng Q., Niu Y., Roubin R.H., Hanrahan J.R. J. Ethnopharmacol., 2009, vol. 124, pp. 350-368.

3. Shetty K., Curtis O.F., Levin R.E., Witkowsky R., Ang W. J. Plant Physiol., 1995, vol. 147, pp. 447-451.

4. Olennikov D.N., Tankhaeva L.M., Partilkhaev V.V. Chem. Nat. Compd., 2012, vol. 47, no. 6, pp. 988-990.

5. Olennikov D.N., Partilkhaev V.V. J. Planar Chrom. Modern TLC., 2012, vol. 25, no. 1, pp. 30-35.

6. Hou W., Lin R., Lee T., Huang Y., Hsu F., Lee M. J. Sci. Food Agric., 2005, vol. 85, pp. 615-621.

7. Lu Y., Sun Y., Foo L.Y., McNaab W.C., Molan A.L. Phytochemistry, 2000, vol. 55, pp. 67-75.

8. Ma Ch., Li B., Xu Q., Zhang G. Chin. J. Appl. Environ. Biol., 2006, vol. 12, pp. 487-495.

9. Boinik V.V., Batyuk N.V., Kovalev V.N. Chem. Nat. Compd., 1986, vol. 22, p. 351.

10. Butayarov A.V., Batirov E.Kh., Tadzhibaev M.M., Yuldashev M.P. Chem. Nat. Compd., 1999, vol. 35, pp. 628-630.

11. Shi J., Chen B., Sun Z.H., Hu C.Q. Acta Pharm. Sin., 2003, vol. 38, pp. 599-602.

12. Umarov A., Batyuk V.S., Khaletskii A.M. Chem. Nat. Compd., 1971, vol. 7, pp. 499-500.

13. Yang Z., Xiao A., Zhang X., Li T., Li S. J. Chin. Med. Mater., 2008, vol. 31, pp. 855-857.

14. Polovinko A.E., Yakovlev G.P. Chem. Nat. Compd., 1985, vol. 21, pp. 252-253.

15. Tai Z.-G., Cai L., Dai L., Sun W.-J., Zhe W., Yang Y.-B., Cao Q.-E., Ding Z.-T. Molecules, 2010, vol. 15, pp. $6722-6732$.

16. Shpekina G.A. Chem. Nat. Compd., 1990, vol. 26, p. 95.

17. Boinik V.V., Kovalev V.N. Chem. Nat. Compd., 1987, vol. 23, p. 504.

18. Polovinko A.E., Shostakovskaya N.G. Chem. Nat. Compd., 1987, vol. 23, p. 375.

19. Qiu E.C., Xiang X.Z., Pan J.C., Tu Z.B. J. Hebei Norm. Univ. (Nat. Sci. Ed.), 1997, vol. 21, pp. 99-101.

20. Ma C.W., Ham I., Whang W.K. Yakhak Hoechi, 1999, vol. 43, pp. 143-149.

21. Iakovlev G.P. Bobovye zemnogo shara. [Legumes of the world]. Leningrad, 1991, pp. 108-112. (in Russ.).

22. Wang J., Gao H., Zhao J., Wang Q., Zhou L., Han J., Yu Z., Yang F. Molecules, 2010, vol. 15, pp. 5998-6007.

23. Gaara A.H., Nassar M.I., Younis M., Elmegeed G.A., Mabry T.J., Pare P.W. Rev. Latinoamer. Quím., 2008, vol. 36, pp. 52-59.

24. Patil A.P., Patil V.R. Int. J. Pharm. Res., 2011, vol. 3, pp. 20-23.

\footnotetext{
* Corresponding author.
} 